ISSN 2236-0859

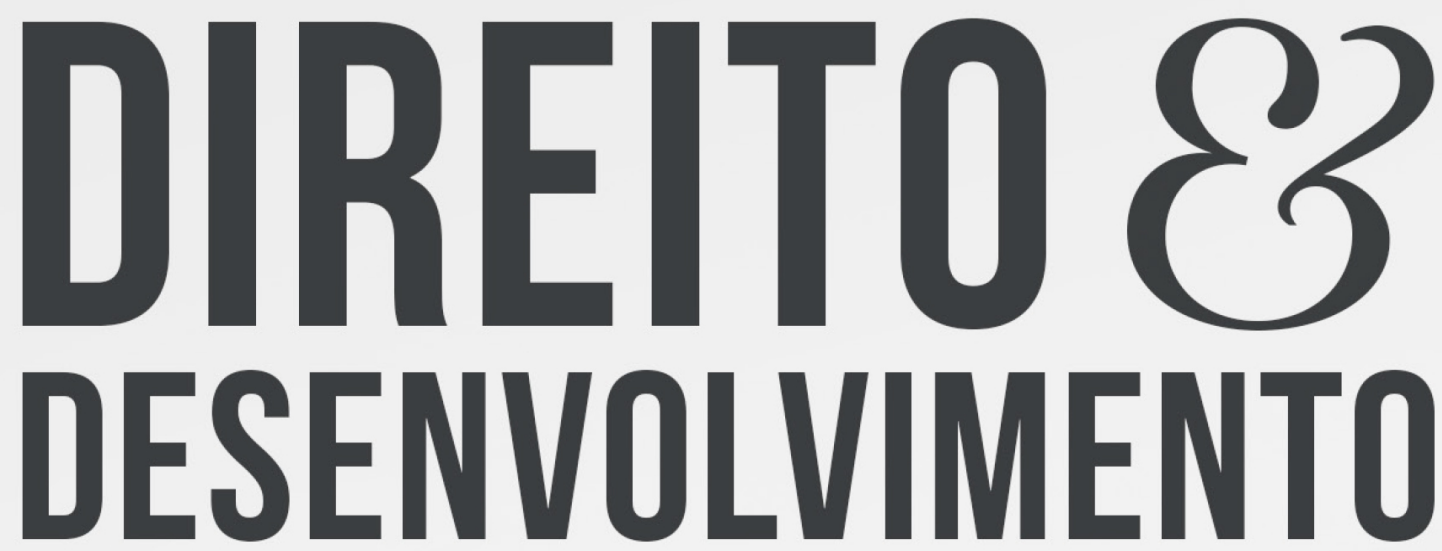

REVISTA DO PROGRAMA DE PÓS-GRADUAÇ̃̃O EM DIREITO MESTRADO EM DIREITO E DESENVOLVIMENTO SUSTENTÁVEL

EMPRESAS ESTATAIS: ALGUMAS CONSIDERACOÕES SOBRE O SEU PAPEL NO DESENVOLVIMENTO ECONÔMICO BRASILEIRO

\author{
GLAUBER DE LUCENA CORDEIRO \\ PAULO HENRIQUE SILVA FIGUEIREDO
}




\title{
EMPRESAS ESTATAIS: ALGUMAS CONSIDERAÇÕES SOBRE O SEU PAPEL NO DESENVOLVIMENTO ECONÔMICO BRASILEIRO
}

\section{STATE-OWNED COMPANIES: SOME CONSIDERATIONS ABOUT YOUR ROLE IN BRAZILIAN ECONOMIC DEVELOPMENT}

Recebido: $28 / 10 / 2020$

Aprovado: 19/12/2020
Glauber de Lucena Cordeiro ${ }^{1}$

Paulo Henrique Silva Figueiredo ${ }^{2}$

\section{RESUMO:}

Este artigo tem por objetivo uma análise histórica do papel desempenhado pelo Estado brasileiro, por meio da atuação de suas empresas, no processo de desenvolvimento econômico nacional. A partir da análise de seis períodos históricos, observa-se qual foi o grau de intervenção praticado por tais entidades na economia, a coerência de tal atuação com o arcabouço constitucional vigente, as motivações ideológicas e pragmáticas que a embasaram e os resultados práticos obtidos. Pretende-se narrar a criação e atuação das empresas estatais no século XX, onde é possível verificar que o seu desenvolvimento se deu de modo descontrolado, muito em face da posição ideológica dos governantes do período, que conduziram à excessos e usos inapropriados de sua atuação em determinados momentos históricos e/ou em setores econômicos específicos. Mas também, não se pode negar que tais entes foram imprescindíveis para garantir a realização de atividades essenciais ao Estado, ante a falta de interesse econômico ou ausência de recursos suficientes por parte da iniciativa privada. Deste modo, procura-se discorrer sobre a existência das estatais para cumprir os papéis que lhe são reservados na ordem econômica constitucional e sobre as perspectivas que as estatais possuem no cenário administrativo atual no país.

Palavras-chave: Estado. Empresas estatais. Análise. Desenvolvimento.

K10o

\begin{abstract}
:
This article aims at a historical analysis of the role of Brazilian State, trough the performance of its state-owned companies, in the process of national economic development. From the analysis of six historical periods, it is possible to observe the degree of intervention practiced by such entities in the economy, the coherence of such action with the current constitutional framework, the ideological and pragmatic motivations that supported it and the practical results obtained. It is intended to describe the creation and performance of state-owned companies in the twentieth 1 Possui graduação em direito pelo Centro Universitário de João Pessoa (200o), Especialização em Direito Tributário pela Universidade Federal de Pernambuco (2003), Mestrado em Ciências Jurídicas pela Universidade Federal da Paraíba (20o8) e Doutorado em Direito pela Universidade do Estado do Rio de Janeiro (2015) (Linha de pesquisa: Direito da cidade). É professor Titular do Centro Universitário de João Pessoa (UNIPÊ), onde foi Coordenador-Adjunto do curso de Graduação em Direito desta Instituição. Coordenador do Programa de Pós-Graduação em Direito do Centro Universitário de João Pessoa - PPGD/UNIPE. Professor Adjunto da Universidade do Estado do Rio Grande do Norte (UERN). email: glauber.lucena@unipe.br

2 Graduado em Engenharia Civil e Ciências Jurídicas e Sociais pela Universidade Federal da Paraíba. Especialista em Direito Tributário, pela Uniderp/Anhanguera. Auditor-Fiscal da Receita Federal do Brasil lotado na Delegacia da Receita Federal do Brasil em João Pessoa/PB. Conselheiro titular, representante da Fazenda Nacional, junto à Primeira Seção do Conselho Administrativo de Recursos Fiscais do Ministério da Fazenda - CARF. Mestrando em Direito e Desenvolvimento Sustentável, pelo Centro Universitário de João Pessoa. email: phsfigueiredo@gmail.com
\end{abstract}


century, where it is possible to verify that their development took place in an uncontrolled way, much in the face of the ideological position of the government of the period, which led to excesses and inappropriate uses of their performance at certain historical moments and / or in specific economic sectors. But also, it cannot be denied that such entities were essential to guarantee the performance of essential activities to the State, given the lack of economic interest or the lack of sufficient resources on the part of the private sector. Thus, it seeks to discuss the existence of state-owned companies to fulfill the roles reserved for them in the constitutional economic order and the prospects that state-owned companies have in the current administrative scenario of Brazil.

Keywords: State. State-Owned Companies. Analysis. Development.

\section{INTRODUÇÃO}

De que tamanho deve ser o aparato estatal? O quanto ele deve intervir na economia? Estas são perguntas que sustentam um debate multidisciplinar histórico e sem qualquer perspectiva de ser encerrado.

Dentro de tal discussão, o presente artigo irá fazer um breve exame, a partir da revisão bibliográfica e do exame da legislação, do papel atribuído e desempenhado pelo Estado Brasileiro em busca de seu objetivo constitucional do desenvolvimento nacional (art. $3^{\circ}$, inc. III da CF/88), em especial, a abordagem de sua intervenção na Economia, por meio das empresas de sua propriedade.

Tais empresas são os próprios espelhos da forma de intervenção estatal direta na economia, quando o Poder Público decide se revestir da qualidade de sujeito econômico empresarial de determinado setor, desde que tal posição seja necessária em função dos requisitos constitucionais do imperativo da segurança nacional ou do relevante interesse coletivo (art. 173, caput). As empresas estatais, aceitas em seu papel por uns e rejeitadas por outros, tem participado do cenário administrativo-econômico do país desde os tempos do Brasil-colônia, tendo algumas existindo até o presente, como Casa da Moeda do Brasil, entidade que hoje é constituída como empresa pública, fundada em 1694. Independente da função que elas exercem, seja na implementação de um serviço público para a coletividade ou na exploração de determinada atividade econômica, as empresas estatais têm sido importante instrumento de personificação do Estado nas relações com sua população - em especial, no que se refere a implementação de várias políticas públicas voltadas às mais diversas camadas sociais -, e com os agentes econômicos do capital privado, no que tange ao exercício da atividade empresarial nos seus diferentes setores de atuação.

Metodologicamente, o presente arrazoado constitui-se como pesquisa qualitativa desenvolvida basicamente através na análise bibliográfica de textos doutrinários sobre a temática central, bem como das normatizações jurídicas inerentes às empresas estatais no país em determinados períodos históricos até chegar a atual regulamentação geral para elas, a Lei Federal n. 13.303/16 (Estatuto jurídico das empresas estatais). Apresenta-se com a seguinte estruturação: são nove itens, cujo primeiro é esta introdução. No segundo será apresentado um breve resumo dos termos e conceitos relacionados à intervenção estatal na economia, em especial aqueles prescritos da doutrina de Eros Roberto Grau; para fomentar, após, a discussão sobre o papel das empresas estatais nessa área. No item seguinte será relacionada algumas linhas sobre tais empresas e o seu posicionamento jurídico no ordenamento federal brasileiro. 
Em seguida, a partir da identificação dos seis períodos temporais relativamente homogêneos que serão distribuídos no decorrer desse texto, os itens versarão sobre os principais pontos que relacionam as empresas estatais dentro na intervenção direta do Estado brasileiro na economia, realizando um exame dos conceitos ideológicos e finalidades práticas que motivaram o incremento ou redução da participação das estatais no fomento ao desenvolvimento do país, buscando um cotejo com as Constituições vigentes e com o ordenamento infraconstitucional. Abordar-se-ão, simultaneamente e de forma crítica, os resultados concretos observados e a importância do papel desempenhado pelas estatais.

O artigo será concluído com uma síntese geral de todos os fatos observados e das conclusões extraídas a partir destes, tentando apontar os pontos favoráveis e desfavoráveis mais expressivos à atuação das empresas estatais como mecanismo de promoção do desenvolvimento. Deve-se ressaltar que o objetivo central do presente texto é trazer uma visão exordial sobre a matéria apresentada, sendo um contributo para ampliação do debate acadêmico sobre o papel daquelas empesas no desenvolvimento econômico nacional.

\section{CONCEPÇÕES ACERCA DA ATIVIDADE ECONÔMICA, ATUAÇÃO E INTERVENÇÃO ESTATAL}

Antes de se adentrar no objeto específico da presente abordagem, faz-se necessária uma breve delimitação acerca de conceitos envolvidos na atuação do Estado por meio das suas empresas e do tratamento dado ao tema no ordenamento constitucional pátrio vigente.

Assim, valendo-se da lição de Grau (2018, pp. 98-10o), é possível estabelecer, inicialmente, a relação entre serviço público e atividade econômica. Aquele seria espécie de atividade econômica - entendido este último termo, em sentido amplo, como um gênero, significando meio pelo qual consiga satisfazer uma necessidade humana individual ou coletiva - cuja realização preferencialmente incumbiria ao Estado. De outra parte, a expressão "atividade econômica" também pode ser compreendida em um sentido estrito, quando estaria, tanto quanto o serviço público, debaixo da atividade econômica em sentido amplo. Sob esta ótica, a atividade econômica (stricto sensu) seria aquela de competência preferencial do setor privado.

O exame do texto da Constituição Federal de 1988 permite a identificação da classificação concebida por Eros Grau para o termo "atividade econômica", quando se observa que o Capítulo I do Título VII (Dos princípios gerais da ordem econômica), trata da atividade econômica em seu sentido amplo, aí incluídos o serviço público e a atividade econômica stricto sensu. Já nos art. 170, parágrafo único, e o art. 173, caput e §1ํㅜㅇ por exemplo, tem-se a atividade econômica abordada em seu sentido estrito.

Entendida a referida distinção, é possível se extrair que a Constituição de 1988 reserva ao Estado, de modo geral, o papel de prestador de serviço público, diretamente ou por meio de concessões e permissões (art. 175) e explicita atividades econômicas, em sentido estrito, que serão por ele exercidas em caráter de monopólio (art. 177) ou o faz genericamente na possibilidade de concorrer com a iniciativa privada, mas desde que observado o princípio da subsidiariedade econômica. Isso significa que a atividade econômica, em sentido estrito, é destinada à iniciativa privada, nele podendo operar o Estado, de forma excepcional, exclusivamente, por razões de segurança nacional ou relevante interesse coletivo (art. 173, caput)3. Em relação a tal concepção de atividade econômica (stricto sensu), o papel

3 É importante ressaltar que a forma direta de intervenção estatal em nosso país deve ser subsidiária e excepcional, mesmo nos casos da proclamação de monopólio do Estado em determinado setor, tanto o é que tais hipóteses necessariamente são prescritos no Texto da Carta Magna, pois o fundamento econômico a ser proclamado em qualquer sistema capitalista, mesmo não sendo tão liberal 
preponderante do Estado será o de atuar como seu agente normatizador, regulador e fiscalizador (art. 174). Por fim, a Constituição possibilita que determinados serviços públicos possam ser desempenhados também pela iniciativa privada, a exemplo da saúde (art. 199), da educação (art. 209), previdência (art. 202) permitindo-se a atuação empresarial nesses setores. A esses, denomina Grau (2018, p. 118) "serviços públicos não privativos".

Estabelecidos os referidos conceitos, cabe finalizar apontando, apenas, a distinção entre aquilo que se compreende como atuação e intervenção estatal. A atuação seria o desempenho pelo Estado de atividade econômica em sentido amplo, aí incluídas, portanto, a prestação de serviço público e a atuação na atividade econômica stricto sensu que lhe foi reservada por monopólio ou naquela em que se realizará em competição com a iniciativa privada, nos casos permitidos pela Constituição. Já a intervenção estatal se destinaria a designar esta última forma de atuação do Estado, ou seja, quando exercerá atividade que não lhe caberia ordinariamente, atividade econômica em sentido estrito; ou, ainda, quando agindo sobre a atividade econômica no seu papel de agente regulador e normatizador (GRAU, 2018 p. 140).

Neste sentido, tomando por base a classificação prescrita por Eros Grau (2018, p. 141142)4, a intervenção estatal se dará por meio de quatro modalidades: por absorção (quando desempenha atividade econômica stricto sensu sob a condição de monopólio), por participação (quando exerce atividade econômica stricto sensu em competição com a iniciativa privada), por direção (quando estabelece normas disciplinando o exercício da atividade econômica) e por indução (quando promove o estabelecimento de estímulos ou desincentivos ao desempenho da atividade econômica). Se for espelhar a classificação disposta no texto da Lei Maior de 1988 com estas doutrinariamente trazidas acima, a intervenção por absorção e participação se configuram dentro da forma direta (art. 173), já a direção e a indução seriam exemplos da intervenção indireta do Estado (art. 174).

Prestados os esclarecimentos conceituais acima, pode-se compreender que, ao tratarmos da atuação do Estado por meio das empresas estatais, estar-se-á referindo diretamente, conforme a classificação prescrita por Eros Grau (2018, pp.141-144), à intervenção do estado na atividade econômica stricto sensu por meio das modalidades por absorção e por participação, sendo possível, ademais, abarcar também intervenção estatal por indução, quando tais entes promovem atividades que incentivam o desempenho de outras atividades econômicas pela iniciativa privada.

\section{EMPRESAS ESTATAIS}

Para a doutrina tradicional do direito administrativo nacional, as empresas estatais são "todas as entidades, civis ou comerciais, de que o Estado tenha o controle acionário" (DI PIETRO, 2019, p. 549). Assim, a partir dos conceitos trazidos desde o Decreto-Lei oㅡ 200/67, as empresas estatais abrangeriam as empresas públicas, assim entendidas aquelas sociedades organizadas sob qualquer forma admitida no direito, cujo capital social seja exclusivamente estatal; e as sociedades de economia mista, compreendidas como as sociedades anônimas cuja maioria do capital social seja detido pelo Estado.

Não obstante, ao longo da história, verificou-se a criação de diversas empresas estatais que não se enquadram perfeitamente aos tipos acima tratados. Assim, apenas para se restringir a algumas das espécies elencadas por Aragão (2018, pp. 106-130), tem-

como o nosso, é o da livre iniciativa (art. 2, inc. IV e 170, caput, da CF/88). Ao Estado, resta o papel inicial de figurante. Só assumindo o protagonismo quando houver uma necessidade coletiva de sua atuação ou quando a iniciativa privada não se interessar por atuar em determinado setor. Ainda assim, sem buscar ampliar demais seu estrelato. (CORDEIRO, 2009, p. 67)

4 Ressalte-se que autor distingue apenas três modalidades de intervenção do Estado na economia, tratando conjuntamente as formas de absorção e participação. 
se: empresas constituídas pelo Estado sem observação das regras impostas às empresas públicas e sociedades de economia mista (a exemplo da prévia autorização legislativa); empresas constituídas com outras nações; e empresas em que o Estado detenha participação minoritária. O Estatuto Jurídico das Empresas Estatais (Lei oㅡ 13.303/16) não enquadra estas últimas sociedades no âmbito das empresas públicas ou sociedades de economia mista (DI PIETRO, 2019, p. 557), nem lhes reserva denominação específica. Aragão (2018, p. 360), contudo, chega a propor uma nova espécie de empresas estatais, as "empresas públicoprivadas”, assim entendidas aquelas sociedades com participação minoritária do Estado. Para outros, a situação não é digna de tal distinção, de modo que tais sociedades seriam tãosomente empresas privadas (DI PIETRO, 2019, p. 557).

De todo, dada que a preocupação fundamental do presente texto é observar a intervenção do Estado na Economia por meio de suas empresas e a relação destas com o desenvolvimento ao longo da história nacional; exclusivamente para seus fins, entender-se-á a expressão "empresas estatais", como sendo todas as entidades empresariais em que o Estado detenha qualquer forma de participação, sem a preocupação com a classificação específica estabelecida no direito administrativo.

\section{PRIMÓRDIOS DA INTERVENÇÃO ESTATAL NO BRASIL: SÉCULO XIX ATÉ DÉCADA DE 1930}

A história da intervenção estatal no Brasil através das empresas estatais tem-se seu relevo ainda no tempo do Brasil-colônia, com a chegada da família real portuguesa, em 1808. A presença da Corte no país demandou, por óbvio, diversas medidas de (re)estruturação da organização administrativa e econômica até então organizadas. Neste contexto, era necessária a existência de instituição destinada a centralizar e agilizar a circulação de moeda, auxiliar o financiamento do crescente aumento do custo do aparato estatal, além de ser fundamental o fomento da atividade manufatureira recém liberada e do comércio de produtos cujo monopólio era detido pela Coroa, razão pela qual, em 12 de outubro do mesmo ano, dentro de tal contexto, criou-se o Banco do Brasil (CARDOSO, 2010, p. 169-170).

Embora pelo projeto original, suas ações seriam adquiridas por capitalista privados, ante a tímida procura, a Real Fazenda, em 1812, passou a ser seu acionista e os recursos dos impostos passaram a ser responsáveis pelo aporte de fundos no capital do Banco (LOBO, 2012). Sua sobrevivência, contudo, estava intimamente relacionada à presença do prínciperegente no Brasil, cujo patrimônio servia de lastro à instituição, de modo que, alguns anos após ao seu retorno a Portugal, ocorreu a sua liquidação e fechamento. O Banco do Brasil - na verdade, uma nova instituição com o mesmo nome - somente retornaria ao controle estatal em 1905.

Já no Brasil-Império, outra empresa estatal, também de atuação no mercado financeiro, foi instituída, a Caixa Econômica Federal, em 1861, cujo propósito era o fomento da poupança e a concessão de empréstimos. Nessa fase histórica, constatava-se a vigência de constituições eminentemente liberais (1824 e 1891), que não utilizavam tantas prescrições de natureza econômica intervencionista, e a intervenção estatal realizada normativamente apenas em nível infraconstitucional. A presença estatal na economia da época era realizada de modo bem peculiar, em setores estratégicos ao desenvolvimento nacional, em especial, o de transportes. Assim, a forma de intervenção preferencial do Estado se deu através da concessão de subsídios a empresas privadas, de modo a estimular as atividades essenciais na incipiente economia (MUSACCHIO; LAZZARINI, 2015, n.p). Exemplo de tal forma de intervenção se deu no setor 
de navegação. Com projeto aprovado em 1888, readequado em 1890, após a proclamação da República, criou-se o Lloyd Brasileiro, sendo a junção das pequenas empresas existentes à época em uma Companhia subsidiada pelo Estado. Já em 1893, porém, devido às dificuldades financeiras, o Lloyd foi nacionalizado. Após breve retorno à iniciativa privada (1901-1913), voltou ao controle exclusivo do Estado em 1913. Entre 1920 e 1937, aquela entidade teve nova passagem à iniciativa privada, para, neste último ano, retornar ao controle estatal, no qual permaneceu até a sua extinção em 1997 (GOULARTI FILHO, 2009).

Experiência semelhante se verificou no setor ferroviário, no qual o Governo forneceu vários incentivos à atuação da iniciativa privada, ao longo do Brasil-Império. Por meio de tal forma de atuação, além do estímulo a entrada de capital estrangeiro no país, houve o desenvolvimento da infraestrutura essencial ao mercado exportador. Após a proclamação da República, houve uma crescente transferência do setor ao comando direto do Estado. Bauer, Kerstenetzky e Villela (1973 p. 885) apontam que, a partir da constatação do excessivo peso da política de subsídio, o Estado optou, mediante a obtenção de empréstimos no exterior, por nacionalizar algumas ferrovias, a partir de 1906, chegando até o controle da maior parte da malha ferroviária, ao final do período.

Finalmente, também essa fase foi marcada pelo surgimento, nas décadas de 19201930, de alguns bancos estatais nos Estados da Federação, visando ao apoio ao setor agrícola de tais entes (BAUER, KERSTENETZKY e VILLELA, 1973, p. 886).

Ao se examinar tal período, a constatação é que a participação estatal na economia se dava de modo contido e pontual, destinada à garantia do estabelecimento e desenvolvimento da infraestrutura básica, bem como ao fomento da economia nacional, setores cuja sustentabilidade econômica era inviável sem o apoio estatal (BAUER, KERSTENETZKY e VILLELA, 1973 p. 884). Em essência, salvo as referidas exceções, manteve-se um regime de laissez-faire baseada nas ideias liberais de pouca intervenção. Porém, essa sistemática tem profunda modificação a partir da década de 30 do século passado, quando o Estado brasileiro começa a adotar um papel mais interventivo na economia, sendo as empresas estatais um importante personagem desse processo, como se verá no item a seguir.

\section{ESTADO EMPREENDEDOR: DÉCADAS DE 1930 A 1950}

A crise econômica mundial de 1929 e a teoria de John Maynard Keynes, defendendo a atuação do Estado na Economia, no sentido de ampliar o emprego e a renda, são fortes ingredientes desta fase histórica de transformação do antigo posicionamento estatal. Aliado a isto, em boa parte do período, o Brasil esteve sob o governo de característica nacionalista de Getúlio Vargas, o denominado Estado Novo, que se valeu do Estado para robusto investimento na industrialização, amparando a política de substituição de importações.

O panorama normativo constitucional não deixou de refletir tal pensamento econômico. Já na Constituição de 1934, constata-se a grande abertura para a intervenção estatal na economia, inclusive, através de monopólios. Instalado o Estado Novo, a Constituição de 1937 ampliou consideravelmente a intervenção estatal, principalmente a direta, na tentativa de fomentar o desenvolvimento econômico pelas próprias mãos do Governo.

Constata-se, portanto, de um lado, a utilização das instituições financeiras estatais, a exemplo do Banco do Brasil, como instrumento da expansão do crédito ao setor agrícola e industrial; e, de outro, um forte investimento do Estado em empresas industriais (indústria de base), como forma de mitigar o risco da dependência de importação de matéria-prima e produtos industrializados (MUSACCHIO; LAZZARINI, 2015 n.p). Surgiram, neste período, as 
grandes indústrias nacionais, como: a Companhia Siderúrgica Nacional, de 1941; a Companhia Vale do Rio Doce, de 1942; a Fábrica Nacional de Automóveis, de 1943; e a Companhia Hidroelétrica do São Francisco, de 1945 (KLIASS, 2018, p. 27).

Apesar da nítida investida do Estado como agente direto na economia, ao final de tal período, não se observava, ainda, um grande número de empresas estatais (PINHEIRO; OLIVEIRA FILHO, 1991, p. 7). A atuação estatal foi restrita a determinados setores considerados imprescindíveis ao desenvolvimento nacional, e, em relação ao quais, não havia recursos privados disponíveis e interessados para o investimento necessário e/ou havia o interesse estratégico em mitigar a dependência internacional.

\section{ESTADO DESENVOLVIMENTISTA: DÉCADAS DE 1950 A 1980}

Após a Segunda Guerra Mundial, as ideias emanadas da Comissão Econômica para a América Latina e o Caribe (CEPAL) foram um grande norteador da atuação estatal na economia brasileira. Com lastro na defesa do Estado como grande indutor e norteador do desenvolvimento, teve-se, então, na Segunda Era Vargas e no governo de Juscelino Kubitschek, uma nova fase de criação de empresas estatais.

A ênfase se deu na criação de empresas estatais na área de infraestrutura (transporte, energia e telecomunicações), bem como na produção de matérias-primas básicas, como o aço e o petróleo. O grande símbolo deste momento histórico foi, sem dúvidas, a criação da Petrobrás, em 1953. Contudo, daí também se originaram a Usina Siderúrgica de Minas Gerais, em 1956; as Centrais Elétricas de Furnas, em 1957; a Rede Ferroviária Federal S.A., de 1957, e a Companhia Urbanizadora da Nova Capital do Brasil, em 1956.

Ao lado da criação direta de empresas estatais, o papel do Estado como agente do desenvolvimento foi reforçado com a abertura do Banco Nacional de Desenvolvimento Econômico (BNDE), em 1952, tendo como propósito ser, exatamente, o orientador e formulador de tal política. Era da incumbência deste banco o fornecimento de crédito a longo prazo para investimentos em energia e transportes. Os empréstimos eram formulados com o ingresso da instituição financeira na condição de acionista minoritário das empresas beneficiadas, vindo, porém, em muitos casos a se converter, posteriormente, em acionista majoritário (MUSACCHIO; LAZZARINI, 2015 n.p).

Após a ruptura da ordem institucional, com o golpe militar de 1964, o processo de expansão do número de empresas estatais atingiu o seu auge (MUSACCHIO; LAZZARINI, 2015), com o uso desenfreado da possibilidade de intervenção do Estado, por meio do autoritarismo e da centralização. Datam desse período grandes obras de infraestrutura, a exemplo das Usinas de Itaipu e Angra dos Reis, além dos sistemas de metrôs de grandes cidades. Surgiram, aí, também, grandes holdings do setor de infraestrutura, como a Telebrás, Infraero, Portobrás e Imbel. A enorme expansão na quantidade de empresas estatais em tal fase histórica decorreu, igualmente, da criação de inúmeras subsidiárias de empresas já existentes, porém para atuarem em setores completamente alheios à atuação inicial que motivou o surgimento destas últimas.

Segundo estatística apresentada por Costa e Miano (2013, p. 153), apenas na década de 1960 e metade da década de 1970, teve-se a criação de mais de 270 empresas estatais, contra 35 surgidas até 1950, o que permite a percepção do nível de expansão da intervenção estatal.

Cabe destacar uma importante norma surgida neste período, que se relaciona com a atuação econômica do Estado. Trata-se do Decreto-Lei no 200, de 1967, que conferiu às empresas estatais o mesmo tratamento dispensado às empresas privadas. É em tal norma, também, 
que apareceram os conceitos legais de Empresas Públicas e Sociedades de Economia Mista, como já relatado. As primeiras, de capital exclusivamente público, para o desenvolvimento de atividade econômica por conveniência administrativa ou contingência; as últimas, com maioria do capital do ente público instituidor.

O resultado do novo arcabouço é visto como determinante na recuperação da capacidade de investimento das empresas estatais, propiciando a expansão da sua atuação, por meio da criação de subsidiárias em diversos setores. Ou seja, ao transpor para suas empresas modelos de gestão e tratamento legal próprios da iniciativa privada, o Estado acabou acentuando a sua participação e competição em setores mais lucrativos da economia (PINHEIRO; OLIVEIRA FILHO, 1991, p. 10).

O final desta fase foi marcado pelas consequências do $2^{\circ}$ Choque do Petróleo, que impôs à União o uso das estatais como fonte de moeda estrangeira para o pagamento das importações. Com a alta de juros nos Estados Unidos, em 1981, e a declaração da moratória pelo México, em 1982, teve-se o fechamento das linhas de crédito até mesmo para as empresas estatais (MUSACCHIO; LAZZARINI, 2015, n.p). Como resultado, dentro das medidas impostas pelo Banco Mundial e pelo Fundo Monetário Internacional (FMI), como exigências para a prestação de auxílio financeiro ao país, constaram o estabelecimento de rígidos limites às empresas estatais. A grave crise econômica, com hiperinflação, controle de preços e recessão comprometeram a lucratividade das empresas estatais, motivaram a descrença no Keynesianismo e acentuaram a pressão pela redução da atuação estatal.

Em linha com este processo, teve-se a instituição do Programa Nacional de Desburocratização, em 1979, pelo Decreto no 83.740, de julho daquele ano. Cabe destacar de tal norma alguns dispositivos que refletiam o propósito de disciplinar e reduzir a atuação do Estado, por meio de suas empresas:
Art $.3^{\circ}$ - O programa terá por objetivo:
(...)
e) intensificar a execução dos trabalhos da Reforma Administrativa de que trata o Decreto-lei no 200, de 25 de fevereiro de 1967, especialmente os referidos no Título XIII; f) fortalecer o sistema de livre empresa, favorecendo a empresa pequena e média, que constituem a matriz do sistema, e consolidando a grande empresa privada nacional, para que ela se capacite, quando for o caso, a receber encargos e atribuições que se encontram hoje sob a responsabilidade de empresas do Estado;
g) impedir o crescimento desnecessário da máquina administrativa federal, mediante o estímulo à execução indireta, utilizando-se, sempre que praticável, o contrato com empresas privadas capacitadas e o convênio com órgãos estaduais e municipais;
h) velar pelo cumprimento da política de contenção da criação indiscriminada de empresas públicas, promovendo o equacionamento dos casos em que for possível e recomendável a transferência do controle para o setor privado, respeitada a orientação do Governo na matéria.

Observe-se que, neste primeiro instante, ainda eram tímidas as intenções de se reduzir o número de empresas estatais. O foco principal se mantinha no aumento do controle e na contenção da expansão desenfreada, posto que era imenso o descontrole a que estavam submetidas as empresas estatais até este momento. Não se sabia, com precisão, o número de empresas, onde atuavam e quais os seus resultados. Daí a razão da criação da Secretaria de Controle de Empresas Estatais (Sest), em 1979 (MUSACCHIO; LAZZARINI, 2015, n.p).

A passagem seguinte traz um dado que impressiona e mostra o nível de descontrole vigente, com base apenas em dados das estatais da União: 


\begin{abstract}
Em seu primeiro censo, a Sest identificou 505 instituições sob controle público federal, sendo cerca de metade delas (268) empresas estatais. Como evidência do processo caótico de formação das estatais na década de 7o, é interessante observar que apenas 40 dessas empresas estatais havia sido criadas por lei. Das outras 228, exatamente um terço eram empresas que havia pertencido ao setor privado e tinham sido assumidas pelo setor público quando em processo de falência (PINHEIRO; OLIVEIRA FILHO, 1991, p. 21).
\end{abstract}

Com o Decreto no 86.215, de 1981, que estabeleceu "normas para a transferência, transformação e desativação de empresas sob o controle do Governo Federal", aí sim, iniciaram-se as medidas de redução do aparato estatal de intervenção na economia. Contudo, continuava presente, explicitamente, na referida norma, a preocupação de resguardar a posição do Estado como viabilizador e controlador do desenvolvimento econômico nacional. O texto do Decreto revela que a ideologia desenvolvimentista ainda era predominante, posto que, ao resguardar determinados setores, o Estado ainda era visto não como um competidor com a iniciativa privada, mas como o impulsionador do seu desenvolvimento (ALMEIDA, 2014, p. 373). A par disso, havia a preocupação nacionalista, ao restringir a possibilidade de aquisição aos cidadãos brasileiros com residência no país ou empresas ou grupos empresariais sob controle nacional.

Por fim, já na era democrática, o Decreto no 91.991, de 1985, instituiu um programa de privatização marcado pelas mesmas restrições gizadas acima. Porém, inovava ao vedar a criação de novas empresas estatais pela União, bem como a aquisição de empresas privadas por empresas não financeiras controladas por aquele ente estatal, além de estabelecer uma série de restrições a novas participações societárias do Estado no setor privado.

O resultado prático de tal política nos governos de João Figueiredo e José Sarney foi bastante tímido, em termos de redução do número de empresas. Houve apenas trinta e oito privatizações de estatais federais no período, sendo o maior efeito a contenção da acelerada expansão de sua quantidade (COSTA; MIANO, 2013, pp. 155-158). Por outro lado, no mesmo período, várias empresas, assoladas pelas dificuldades financeiras, passaram ao controle estatal, por meio do BNDES, sendo que parte destas foram exatamente aquelas incluídas no processo de privatização.

\title{
7 PRIMEIRA FASE DE DESESTATIZAÇÃO: 1990 A 2002
}

Como já comentado, a Constituição Federal de 1988 trouxe, como regra, a reserva das atividades econômicas à iniciativa privada, com o Estado atuando como agente normativo e regulador. A atuação direta estatal ficou restrita à motivação por segurança nacional, bem como em decorrência de relevante interesse coletivo. Kliass (2018, p. 29-30) aponta três argumentos utilizados, a partir de então, para a defesa da redução da atuação estatal na economia. Em primeiro lugar, obviamente, no plano ideológico, tem-se a influência das ideias liberais, alinhadas com o denominado "Consenso de Washington", com a proposta de liberalização, desregulamentação e transferência das empresas estatais para a iniciativa privada. Até mesmo a transição do regime autoritário para a democracia é utilizada para defender que um novo modelo deveria ser imposto, desfazendo o forte crescimento da presença do Estado na economia verificado no período ditatorial.

Além disso, um segundo argumento seria a suposta menor eficiência da atuação do Estado naquele setor em relação à iniciativa privada, cuja consequência seria a alteração do normal comportamento dos agentes econômicos e a distorção de elementos basilares 
da macroeconomia (tais como preços, renda e oferta). Mais uma vez, a solução viria pela transferência ao setor privado das empresas estatais, o que resultaria em livre funcionamento do mercado, com ganhos de qualidade e competitividade. Para os setores que funcionam em regimes de monopólio ou oligopólio, a solução viria por meio da atuação das agências reguladoras.

Por fim, o argumento final, que seria o mais pragmático: a crise fiscal. Sem recursos para o adequado investimento nas suas empresas, o Estado poderia, com as privatizações, reduzir o seu número e a sua necessidade de recursos para sua manutenção, ao tempo que reforçaria o seu caixa com os ingressos oriundos da alienação desses ativos, ou mesmo, saldar parte ou integralmente algumas de suas dívidas, para deixá-lo mais saneado financeiramente.

Em linha com tal pensamento, teve-se o lançamento, por meio da Lei no 8.031 , de 1990, do Programa Nacional de Desestatização (PND), cujos objetivos fundamentais eram apresentados no art. $1^{\circ}$ daquela norma. In verbis:

\footnotetext{
Art. $1^{\circ}$ É instituído o Programa Nacional de Desestatização, com os seguintes objetivos fundamentais:

I - reordenar a posição estratégica do Estado na economia, transferindo à iniciativa privada atividades indevidamente exploradas pelo setor público;

II - contribuir para a redução da dívida pública, concorrendo para o saneamento das finanças do setor público;

III - permitir a retomada de investimentos nas empresas e atividades que vierem a ser transferidas à iniciativa privada;

IV - contribuir para modernização do parque industrial do País, ampliando sua competitividade e reforçando a capacidade empresarial nos diversos setores da economia;

$\mathrm{V}$ - permitir que a administração pública concentre seus esforços nas atividades em que a presença do Estado seja fundamental para a consecução das prioridades nacionais; VI - contribuir para o fortalecimento do mercado de capitais, através do acréscimo da oferta de valores mobiliários e da democratização da propriedade do capital das empresas que integrarem o Programa.
}

A análise a posteriori dos resultados do referido programa, porém, revela a sua concentração em empresas relativamente lucrativas e com atuação em setores estratégicos, a exemplo da Usiminas, da Companhia Siderúrgica Nacional (CSN) e da Embraer. A par disso, ao acatar o pagamento do preço por meio das denominadas "moedas de privatização" (títulos públicos e debêntures), o resultado financeiro obtido terminou por se mostrar pífio: apenas $19 \%$ dos valores pagos foram realizados em espécie (MUSACCHIO; LAZZARINI, 2015, n.p). A quantidade de empresas alienadas em decorrência do PND também não se revelou expressivo: 33 empresas. Porém, várias delas eram de relevante peso econômico nos seus respectivos setores.

Costa e Miano (2013, p. 160) apontam mais uma crítica às privatizações ocorridas nos Governos de José Sarney, Fernando Collor e Itamar Franco. É que, ao se concentraram na busca por melhores resultados fiscais, terminou-se sem se avançar, efetivamente, no debate acerca do papel desejado para o Estado na Economia, como se tinha por objetivo quando do estabelecimento do PND.

Com o Governo de Fernando Henrique Cardoso, o enfoque neoliberal foi reforçado com os progressos no estabelecimento do Estado como agente regulador e diminuição de sua intervenção direta na economia. Nesta linha, promoveu-se a terceira onda de privatizações, cujo foco foram as empresas de telecomunicações, eletricidade e parte das financeiras. Aliado a isso, efetivou-se a concessão de portos, e parte da infraestrutura de transporte e saneamento (MUSACCHIO; LAZZARINI, 2015, n.p). 
Dentro deste processo, houve decisiva participação do Banco Nacional de Desenvolvimento Econômico e Social - BNDES (nova denominação do BNDE), atuando como agente operacional e financiador de alguns compradores, bem como através da aquisição de participações minoritárias nas empresas alienadas. A crítica, porém, é que tal atuação se deu em favorecimento a grandes grupos empresariais, que poderiam ter participado do processo, mesmo sem qualquer tipo de auxílio por parte do Banco (MUSACCHIO; LAZZARINI, 2015, n.p). Para alguns estudiosos:

(...) o resultado das reformas liberalizantes da década de 1990 foram desiguais. A expansão dos investimentos privados em infraestrutura ficou muito restrita aos segmentos mais atraentes e, na maioria dos demais segmentos, o avanço privado não se refletiu no aumento dos investimentos em magnitude suficiente para compensar a queda nos gastos públicos. Explicitando-se uma incapacidade de se alocar recursos na manutenção e expansão da infraestrutura do país, recolocando gargalos ao crescimento, prejudicando a competitividade sistêmica e contribuindo para o fraco crescimento econômico do período. Mais do que mera transferência de responsabilidades à iniciativa privada, houve reconcentração setorial e reconfiguração das articulações entre investimento público e privado, cabendo ao Estado, em conformidade com esse diagnóstico, assumir uma posição mais pragmática para promover a retomada dos investimentos, via intervenção direta ou indireta, por meio de arranjos remodelados com o setor privado, nos quais as empresas, bancos e fundos públicos desempenhariam papel proeminente. (ORAIR; SIQUEIRA, 2018, p. 8)

Sob essa ótica, as empresas estatais foram diminuindo o seu papel na economia estatal, graças à instalação dos preceitos neoliberais já aqui traduzidos. Porém, na primeira década desse século, há um redimensionamento das concepções político-econômicas no país, com a ascensão ao poder de um governo de centro-esquerda, que faz reavaliar o posicionamento descendente que as empresas estatais tinham na economia. Tal período será relatado no próximo item.

\section{O NOVO DESENVOLVIMENTISMO: 2006 A 2016}

A ascensão do Partido dos Trabalhadores ao Governo, em 2003, manteve, em um primeiro momento, um alinhamento com o programa macroeconômico herdado do período anterior (CURADO, 2013, p. 73; PINHO, 2017, p. 339), o que não resultou em significativas alterações em relação ao papel desempenhado pelas empresas estatais na Economia.

Em 2006, contudo, com a substituição do Ministro da Fazenda (saída de Antônio Palocci e entrada de Guido Mantega), observou-se uma inflexão que trouxe de volta ideias inspiradas na doutrina keynesiana, com a acentuação do papel do Estado como promotor do desenvolvimento da economia (NOVY, 2009, p. 123). O fracasso das políticas ortodoxas em promover o crescimento da economia conduziu ao abandono das concepções neoliberais em favor do renascimento da visão desenvolvimentista (PINHO, 2017, p. 340).

Como dito, esta nova fase foi profundamente caracterizada pelo resgate do protagonismo das empresas estatais como agentes do desenvolvimento, bem como pelo papel desempenhado pelos bancos públicos no incremento da oferta de crédito ao mercado (MORAIS; SAAD-FILHO, 2011, p. 517-518). Um exemplo nítido dessa nova política foi o Programa de Aceleração do Crescimento (PAC), por meio do qual, com base em investimentos diretos do Estado, ou a partir de financiamentos do BNDES, foram promovidos substanciais investimentos em infraestrutura (PINHO, 2017, p. 340-341). 
De destacar, ainda, dentre as estatais, o papel da Petrobrás, posta como única operadora na exploração e detentora de participação mínima de 30\% em todos os blocos de operação na área do pré-sal (LOPREATO, 2015, p. 240).

Esta fase foi caracterizada, ademais, pela formação, com apoio estatal, dos chamados "campeões nacionais", empresas que recebiam benefícios, notadamente recursos oriundos do BNDES, para promoverem a concentração em setores específicos, de modo a se tornarem competitivas local e internacionalmente com as grandes multinacionais estrangeiras.

Por fim, o período em questão registrou uma grande quantidade de concessões de serviços públicos e formação de parcerias público-privadas (PPP), ao lado da criação de novas empresas estatais, em um abandono do tradicional esquema de privatização utilizado ao longo da fase neoliberal.

A análise de tal fase, em especial dos governos de Luís Inácio Lula da Silva, mostra que a política desenvolvimentista implementada se distinguiu daquela realizada nos períodos históricos anteriores, pela inserção do elemento social, de modo que, em lugar de mero crescimento econômico, foi observado verdadeiro período de desenvolvimento econômico e social. Um "crescimento redistributivo" (PINHO, 2017, p. 342).

OGoverno de Dilma Roussef revelou uma acentuação dessa política desenvolvimentista, inclusive com a criação de novas estatais de atuação na área de infraestrutura: Empresa de Planejamento Estratégico e a Valec Engenharia, Construções e Ferrovias S.A. (PINHO, 2017, p. 348).

Esse processo fez desencadear uma fuga dos investidores privados no país, em função dessa maior participação direta do Estado na atividade econômica. Aliado a isso, a elevação da crise político-institucional no país, deflagrada pelas denúncias de corrupção envolvendo, dentre outras coisas, a maior empresa estatal do Brasil, a Petrobrás S/A, que reveladas pela "Operação Lava-jato", criou um cenário de instabilidade que culminou no processo de impeachment daquele Governo, com a retomada das premissas liberalizantes na economia.

\section{A NOVA FASE NEOLIBERAL: 2016 ATÉ O PRESENTE}

O viés liberal dos novos protagonistas da Economia após a queda do Governo Dilma Roussef, levou-se a uma retomada da defesa da desestatização e a retomada da ideia de privatização das empresas estatais. Em 2016, surge o Estatuto das Estatais (Lei no 13.303), no qual se estabeleceu a exigência de estrita obediência aos limites impostos pelo art. 173 da Constituição Federal, para criação de empresas estatais. Além disso, há a previsão de regras claras de transparência e governança em tais entes, como uma reação aos desvios comprovados do período anterior.

No mesmo ano, teve-se a idealização do Programa de Parcerias de Investimento (PPI), instituído pela da Lei no $\mathbf{1 3 . 3 3 4}$, de 2016, um amplo programa de redução do tamanho do Estado, com o objetivo, ainda, de utilização dos recursos obtidos para a redução da dívida pública.

O clima de instabilidade política e a brevidade do Governo de Michel Temer impediram a obtenção de resultados muito expressivo com o referido Programa. Não obstante, foi a mais significativa redução no número de estatais nos últimos anos, com a redução de 145 para 134 estatais. O Governo terminou, ainda, com uma série de projetos de privatização e concessões qualificados para a implementação.

A equipe econômica do atual Governo de Jair Bolsonaro mantém o alinhamento nessa área com o governo anterior. Assim, levou-se à declaração de pleno aproveitamento 
dos projetos preparados, no âmbito do PPI. Contudo, apesar de a mensagem dirigida ao Congresso Nacional falar em um "amplo programa de privatizações e concessões em todas as áreas relacionadas à infraestrutura" (BRASIL, 2019, p. 18), decorridos mais de quatrocentos dias de governo, observou-se, apenas a realização de leilões de concessões (portos e aeroportos), sem o registro de qualquer empresa estatal privatizada. Deste modo, à data de elaboração do presente artigo, apenas em nível federal, ainda se registra a existência das mesmas 197 empresas estatais, sendo 46 sob controle direto e 151 subsidiárias (BRASIL, 2020).

\section{CONSIDERAÇÕES FINAIS}

A análise histórica da participação das empresas estatais na economia demonstra uma abundância de excessos, descontroles e abusos do papel reservado ao Estado perante a atividade econômica. Ao longo da história, houve desvios enormes do seu campo de atuação que lhe foi destinado pelas Constituições, passando a atuar em direta concorrência com a iniciativa privada e em áreas nitidamente afastadas do seu escopo. Ao lado disso, a sua estrutura empresarial se agigantou e fugiu aos controles, terminando, por se constituir, em algumas vezes, em mecanismo de arrecadação ilícita de recursos para o atendimento de interesses privados e político-partidários.

Não obstante, essa mesma análise revela a importância da atuação estatal como agente preponderante em momentos históricos e/ou em setores econômicos específicos. As empresas estatais cumpriram nestes contextos um papel fundamental no sentido de propiciar a realização de atividades fundamentais ao desenvolvimento nacional, principalmente quando não havia recursos privados disponíveis em montante suficiente ou, a ausência de interesse e lucratividade da iniciativa privada em determinado setor. Assim, nestas áreas, as necessidades públicas, encontraram e encontram no Estado o único agente capaz de realizar os investimentos indispensáveis.

Foi possível, ainda, observa-se, a baixa aderência entre a ordem constitucional vigente e o grau de intervenção do Estado, por meio das suas empresas, pois sob uma mesma Constituição, observam-se ciclos de maior ou menor intervencionismo na economia. No caso, o fator preponderante verificado foi, mesmo, a orientação ideológica dos governos em relação à posição e ao tamanho do Estado empresário.

Por fim, como resultado desta avaliação, constata-se a importância da mitigação da influência política na criação e atuação das estatais, da implantação de rígidos mecanismos de controle no funcionamento destas e da seleção da mais adequada da sua utilização, em prol de uma melhor atuação dessas entidades no setor econômico e da conjuntura macroeconômica do país.

\section{REFERÊNCIAS}

ALMEIDA, Monica Piccolo. A reestruturação do setor público estatal brasileiro rumo às privatizações dos anos 1990. In. Anos 90 - Revista do Programa de Pós-Graduação em História. Porto Alegre, v. 21, n. 39, p. 363-397, 2014. Disponível em: https://seer.ufrgs.br/ anos9o/article/view/31087/30807. Acesso em: 10 jul. 2019. 
ARAGÃO, Alexandre Santos de. Empresas estatais: o regime jurídico das empresas públicas e sociedades de economia mista. 2. ed. Rio de Janeiro: Forense, 2018.

BAER, Werner; KERSTENETZKY, Isaac; VILLELA, Annibal V. As modificações no papel do estado na economia brasileira. In: Pesquisa e planejamento econômico. Rio de Janeiro: IPEA, v. 3, n. 4, p. 883-912, dez. 1973. Disponível em: http://repositorio.ipea.gov.br/ bitstream/11058/6554/1/PPE_v3_n3_As\%2omodifica\%c3\%a7\%c3\%b5es.pdf. Acesso em: 5 jul. 2019 .

BRASIL. Constituição da República dos Estados Unidos do Brasil. Rio de Janeiro, RJ, 16 jul. 1934. Disponível em: http://www.planalto.gov.br/ccivil_03/Constituicao/Constituicao34.htm. Acesso em: 10 jul. 2019.

BRASIL. Constituição da República dos Estados Unidos do Brasil. Rio de Janeiro, RJ, 10 nov. 1937. Disponível em: http://www.planalto.gov.br/ccivil_03/Constituicao/Constituicao37.htm. Acesso em: 10 jul. 2019.

BRASIL. Constituição da República Federativa do Brasil de 1988. Brasília, DF, o5 out. 1988. Disponível em: http://www.planalto.gov.br/ccivil_03/Constituicao/Constituiçao.htm. Acesso em: 10 jul. 2019.

BRASIL. Lei no 13.303 , de 30 de junho de 2016. Dispõe sobre o estatuto jurídico da empresa pública, da sociedade de economia mista e de suas subsidiárias, no âmbito da União, dos Estados, do Distrito Federal e dos Municípios. Brasília, DF, o1 jul. 2016. Disponível em: http:// www.planalto.gov.br/ccivil_03/_ato2015-2018/2016/lei/l13303.htm. Acesso em: 10 jul. 2019.

BRASIL. Ministério da Economia. Panorama das Estatais. Disponível em: http://www. panoramadasestatais.planejamento.gov.br. Acesso em: 24 ago. 2020.

BRASIL. Presidência da República. Decreto no 83.740, de 18 de julho de 1979. Institui o Programa Nacional de Desburocratização e dá outras providências. Brasília, DF, 18 jul. 1979. Disponível em: http://www.planalto.gov.br/ccivil_03/decreto/D83740.htm. Acesso em: 10 jul. 2019.

BRASIL. Presidência da República. Decreto no 86.215, de 15 de julho de 1981. Fixa normas para a transferência, transformação e desativação de empresas sob o controle do Governo Federal, nos casos que especifica. Brasília, DF, 16 jul. 1981. Disponível em: https://www.normasbrasil. com.br/norma/decreto-86215-1981_40844.html. Acesso em: 10 jul. 2019.

BRASIL. Presidência da República. Decreto no 91.991, de 28 de novembro de 1985. Dispõe sobre o processo de privatização de empresas sob controle direto ou indireto do Governo Federal, e dá outras providências. Brasília, DF, 29 nov. 1985. Disponível em: https://www2.camara.leg. br/legin/fed/decret/198o-1987/decreto-91991-28-novembro-1985-442714-publicacaooriginal1-pe.html. Acesso em: 10 jul. 2019. 
BRASIL. Presidência da República. Decreto-Lei no 200, de 25 de fevereiro de 1967. Dispõe sobre a organização da Administração Federal, estabelece diretrizes para a Reforma Administrativa e dá outras providências. Brasília, DF, 27 fev. 1967. Disponível em: http://www.planalto.gov.br/ ccivil_03/decreto-lei/delo2oo.htm. Acesso em: 10 jul. 2019.

BRASIL. Presidência da República. Mensagem ao Congresso Nacional. Brasília: Presidência da República, 2019. Disponível em: https://www.gov.br/planalto/pt-br/mensagemdopresidente/ MensagemaoCongresso2019.pdf. Acesso em: 28 ago. 2019.

CARDOSO, José Luís. Novos elementos para a história do Banco do Brasil (1808-1829): crônica de um fracasso anunciado. In: Revista brasileira de história, São Paulo, v. 30, n. 59, p. 167192, 2010. Disponível em: http://www.scielo.br/pdf/rbh/v3on59/v3on59ao9.pdf. Acesso em: 10 ago. 2019 .

CORDEIRO, Glauber de Lucena. Medidas provisórias econômico-tributárias e o seu conflito com os direitos fundamentais do contribuinte. Recife: Nossa Livraria, 2009.

COSTA, Francisco Lustosa da; MIANO, Vítor Yoshihara. Estatização e desestatização no Brasil: o papel das empresas estatais nos ciclos da intervenção governamental no domínio econômico. Revista de Gestión Pública, Santiago, v. II, n. 1, p. 145-181, jan./jun. 2013. Disponível em: http://www.revistadegestionpublica.cl/. Acesso em: 25 mai. 2019.

CURADO, Marcelo. Do esgotamento do projeto neoliberal ao governo Lula: em busca de um projeto nacional de desenvolvimento. Cadernos do desenvolvimento. Rio de Janeiro, v. 8, n. 12, p. 67-81, jan./jun. 2013. Disponível em: http://www.cadernosdodesenvolvimento.org.br/ ojs-2.4.8/index.php/cdes/article/view/158/156. Acesso em: 05 jul. 2019.

DI PIETRO, Maria Sylvia Zanella. Direito administrativo. 32. ed. Rio de Janeiro: Forense, 2019 .

GOULARTI FILHO, Alcides. Companhia de Navegação Lloyd Brasileiro: Uma trajetória de déficit financeiro e desenvolvimento econômico. In: VIII Congresso Brasileiro de História Econômica, 2009, Campinas. Anais do VIII Congresso Brasileiro de História Econômica e IX Conferência Internacional de História de Empresas. Campinas: ABPHE, 2009. v. 1. Disponível em: http://www.abphe.org.br/arquivos/alcides-goularti-filho_1.pdf. Acesso em: 25 mai. 2019.

GRAU, Eros Roberto. A ordem econômica na constituição de 1988. 19. ed. São Paulo: Malheiros, 2018.

KLIASS, Paulo. O debate sobre a atuação empresarial estatal no país: principais argumentos. Boletim de Análise Político-Institucional, Brasília: IPEA, n. 15, p. 27-31, jul./ dez. 2018. Disponível em: http://repositorio.ipea.gov.br/bitstream/11058/8626/1/BAPI15_Cap2. pdf. Acesso em: 25 mai. 2019.

LOBO, Rodrigo. Banco do Brasil. Set. 2012. Disponível em: http://mapa.an.gov.br/index.php/ dicionario-periodo-colonial/138-banco-do-brasil. Acesso em 20 jul. 2019. 
LOPREATO, Francisco Luiz C. In: CALIXTRE, Bojikian; BIANCARELLI, André Martins; CINTRA, Marcos Antônio Macedo. Presente e futuro do desenvolvimento brasileiro. Brasília: IPEA, p. 227-26o, 2014. Disponível em: http://www.ipea.gov.br/portal/images/stories/ PDFs/livros/livros/150605_livro_presente_futuro.pdf. Acesso em: 25 mai. 2019.

MORAIS, Lécio; SAAD-FILHO, Alfredo. Da economia política à política econômica: o novodesenvolvimentismo e o governo Lula. Revista de Economia Política. São Paulo, v. 31, n. 4, p. 505-527, out./dez. 2011. Disponível em: http://www.scielo.br/pdf/rep/v31n4/o1.pdf. Acesso em: 12 ago. 2019.

MUSACCHIO, Aldo; LAZZARINI, Sergio G. Tradução de Afonso Celso da Cunha Serra. Reinventando o capitalismo de Estado. 1. ed. São Paulo: Portfolio Penguin, 2015. Edição Kindle.

NOVY, Andreas. O retorno do estado desenvolvimentista no Brasil. Tradução de Carlos Roberto Winckler. Indicadores econômicos FEE. Porto Alegre, v. 36, n. 4, p. 121-128, 2009. Disponível em: https://revistas.fee.tche.br/index.php/indicadores/article/view/2248/2604. Acesso em: 10 jul. 2019.

ORAIR, Rodrigo Octávio; SIQUEIRA, Fernando de Faria. Investimento público no Brasil e suas relações com ciclo econômico e regime fiscal. Economia e Sociedade. Campinas: UNICAMP, v. 27, p. 939-969, 2018. Disponível em: http://www.scielo.br/scielo.php?script=sci_ arttext\&pid=So104-06182018000300939. Acesso em: 5 jul. 2019.

PINHEIRO, Armando Castelar; OLIVEIRA FILHO, Luiz Chrystóstomo de. Privatização no Brasil: passado, planos e perspectivas. Rio de Janeiro: IPEA, 1991. Disponível em: http://www. ipea.gov.br/portal/images/stories/PDFs/TDs/td_0230.pdf. Acesso em: 10 ago. 2019.

PINHO, Carlos Eduardo Santos. Planejamento governamental no novo-desenvolvimentismo democrático: auge e deterioração das capacidades estatais (2003-2016). Revista política e planejamento regional. Rio de Janeiro, v. 4, n. 2, p. 331-368, jul./dez. 2017. Disponível em: http://neic.iesp.uerj.br/carlospinho.pdf. Acesso em: 20 ago. 2019. 